\title{
Redefining Our Understanding of The Impact of Firearm-Related Injury in the State of Georgia: A White Paper by the Violence Prevention Task Force of IPRCE
}

\author{
Omar K. Danner MD ${ }^{1}$, Lauren Hudak MD, MPH², Rana Bayakly MPH³ , Carol Koplan MD ${ }^{4}$, Alexander Kelly ${ }^{5}$, Sharon L. Nieb \\ $\mathrm{PhD}, \mathrm{MSW}^{6}$, and Sheryl L. Heron MD, $\mathrm{MPH}^{6}$
}

${ }^{1}$ Department of Surgery Morehouse School of Medicine, Atlanta GA. ${ }^{2}$ Department of Emergency Medicine, Emory University School of Medicine, Atlanta, GA. ${ }^{3}$ Georgia Department of Public Health, Atlanta, GA. ${ }^{4}$ Rollins School of Public Health, Emory University School of Medicine, Atlanta, GA. ${ }^{5}$ Morehouse School of Medicine, Atlanta, GA, and ${ }^{6}$ Injury Prevention Research Center at Emory, Emory University School of Medicine, Atlanta, GA

Corresponding Author: Omar K. Danner, MD, FACS, FCCM, CLSSBB • Professor of Surgery, Vice-Chair of Injury \& Violence Prevention, Georgia Committee on Trauma, Department of Surgery, Morehouse School of Medicine • 720 Westview Drive S.W., Atlanta, GA 30310 • Telephone: (404) 616-1415 • Email: odanner@msm.edu

\section{ABSTRACT}

Background: Firearm-related injury is a crisis that afflicts vulnerable populations of all ages, ethnicities, races and gender. The purpose of this white paper is to delineate the impact of firearm-related violence on the health and well-being of citizens and communities across Georgia based on the available literature and data. The aim of this white paper is to examine and characterize the currently available data on the impact of firearm violence and injury from a statewide perspective, principally as it relates to the National Violent Death Reporting System (NVDRS) report for Georgia.

Materials and method: We performed a literature review to analyze data obtained through the Web-based Injury Statistics Query and Reporting System (WISQARS ${ }^{\mathrm{TM}}$ ) and NVDRS. We used the data to characterize the types and extent of firearm injuries and deaths in the U.S. and Georgia.

Results: We identified an overall mortality rate of $27 \%$ for all-types of firearm injuries. The estimated average annual age-adjusted firearm injury rate was 31.5 per 100,000 people. The case fatality rate for suicide due to firearm injury notably had the highest gun-related mortality rate by greater than 6-fold. Furthermore, from 2015 to 2016, the national mean annual case fatality rate was $84 \%$ for firearm-related suicide according to 2017 CDC report.

Conclusion: Greater investment into research, education and prevention of gun-related violence among citizens in the state of Georgia is necessary. Although firearm-related aggravated assault due to interpersonal violence is common, the case fatality rate due to suicide has a greater than 6-fold higher rate of death.

Keywords: Firearm-related violence, homicide, suicide, Georgia, assault weapons

\section{INTRODUCTION}

Firearm-related injury is a crisis that afflicts vulnerable populations of all ages, ethnicities, races and gender, but traditionally it has been ascribed to young assault victims who have years of potential to become productive members of our society. The purpose of this white paper is to delineate the true impact of firearm-related violence on the health and well-being of citizens and communities across Georgia based on the available literature and information assimilated by the Georgia Department of Public Health (GDPH) and via the Centers for Disease Control and Prevention (CDC) databases. In addition, our goal is to make actionable recommendations for potential strategies, procedures and policies to address the critical gun-violence issue in the State of Georgia based on knowledge and insight gained through this research and outreach efforts. The aim of this white paper is to examine and characterize the currently available data on the impact of firearm violence and injury from a statewide perspective, principally using analysis of data attained from the National Violent Death Reporting System (NVDRS) report for Georgia.

The Injury Prevention Research at Emory (IPRCE), a Centers for Disease Control and Prevention funded Injury Control Research Center currently supports five Task Forces supported a formal faculty mentoring program from 2009-2014. This interdisciplinary group includes representatives from the fields of trauma surgery, emergency medicine, psychiatry, advocacy and public health. In 2015-2016, the program transitioned into an informal mentoring program based around our Task Forces, 
where Task Force and IPRCE leadership worked to pair junior faculty who attended Task Force meetings with senior mentors (both research mentors and public health professionals who facilitate translation of science to practice). Outcomes have included mentoring of a task force leader who, along with her clinical practice is now establishing a career in firearms research, and five VPTF white papers, which include topics on intimate partner violence, elder abuse, teen dating violence, INSERT, and firearm-related injury in Georgia. Additionally, a CDC-funded research project that geographically identifies the location of violent injuries, including the use of firearms, through emergency room data and informs law enforcement of trends is currently underway. Other research studies emerged from the use of an evidence-driven approach, including studies on the impact of e-scooters, alcohol impaired drivers, traumatic brain injury evaluation and management, providing advice and guidance on Georgia's response to the opioid crisis, and seven current research projects related to opioid use, treatment and prevention. Working with the VPTF, we have and will continue to identify and address research gaps, serve as advisory groups for research and prevention efforts of our partners, and act as networks for education and outreach within the domain of violence prevention across the lifespan.

Generating and sustaining interest in cross-training public health professionals requires a continuous effort to sustain interest. Some examples of topics for these lectures are elder abuse, teen dating violence, adolescent suicide, adverse childhood experiences (ACEs), trauma informed care, and the impact of severe acute respiratory syndrome (SARS-Co-V2) due coronavirus disease 2019 (COVID-19) on behavioral health services. Lessons learned from review of firearm-related and other data help to shape the IPRCE lecture series, which provide the opportunity for interdisciplinary training of physicians, research faculty, public health service providers, and Master's/PhD students; and for dissemination of research findings or efficacious programs.

The purpose of this position paper by the VPTF is to assist stakeholders, politicians, and community leaders to better understand and quantify the true impact of firearm-related violence on the health status of the citizens in Georgia in both the general and underrepresented communities. The principal aim of this paper is to elucidate how firearm-related violence and injury due to interpersonal conflict as well as self-harm affects the lives of our citizens as it relates on race, gender and age group.

\section{Statement of the Problem}

The VPTF agrees with other leading medical organizations, such as the American College of Surgeons Committee on Trauma, American Association for the Surgery of Trauma, and American College of Emergency Medicine that firearm-related injury is an important public health problem.
This crisis is more apparent in vulnerable populations of all ages, ethnicities, genders and races, but particularly among young firearm-assault victims who have many years of potential life to become productive members of our state and national workforce. The purpose of the proceeding document is to delineate and characterize the impact of firearm-related trauma on the health and well-being of citizens and communities across Georgia. The basis of this report is on the available information and data from the Georgia Department of Public Health (GDPH) and the National Violent Death Reporting System (NVDRS). This data has been useful to inform and educate community partner organizations on areas requiring greater resources and attention. In addition, we will conclude with recommendations for potential strategies, procedures and policies to address gun-violence.

\section{MATERIALS AND METHODS}

We performed a literature review to analyze data obtained through the Web-based Injury Statistics Query and Reporting System (WISQARS ${ }^{\mathrm{TM}}$ ) and NVDRS. We queried the Center for Disease Control and Prevention's (CDC) WISQARS ${ }^{\mathrm{TM}}$ database to assess violence-related injury data for the years 2015 and 2016. WISQARS ${ }^{\mathrm{TM}}$ is an interactive, web-based database that makes available fatal and nonfatal injury, violent death, and economic-related injury data from a variety of trusted sources. Researchers, public health professionals, media reporters, and the general-public can use WISQARS ${ }^{\mathrm{TM}}$ data to inform themselves and others about the public health and economic burden associated with unintentional and violence-related harm in the United States. Researchers studied, stratified and assessed the injury statistics and generated reports, tables, and plots based on various variables, including injury intent, body area, nature of the trauma, injury mechanism, demographics, and nature of the injury. WISQARSTM includes fatality reports, which show the actual number of trauma-related deaths and the mortality rates by intent and method of harm, geographic location, race, gender, ethnicity and age that helped investigators to characterize the impact of gun-violence. Violent death data obtained from WISQARS detailed the number of violence-related deaths and deaths rates in the participating states as well as geographic regions. It also facilitated analyses and reports of the intent, mechanism, and specific nature of the mortal wound. It further detailed the victims and offenders, veteran status and suicide-related information, which is often, not very well recorded, making WISQARS an important and informative but under-recognized and utilized tool in the violence and injury prevention field for outreach efforts (WISQARS, 2017).

\section{RESULTS}

Characterization of the extent of firearm injuries and deaths in the U.S. has become an increasingly well-tracked and understood phenomenon through efforts by the Centers for 
Disease Control \& Prevention. CDC Data from 2015 and 2016 suggested that on average over 37,000 people die each year in the U.S. from firearm-related injury, for an annual age-adjusted fatality rate of 31.4 per 100,000 . Surprisingly, over $60 \%$ of these in 2016 were suicides $(n=22,478), 37 \%$ were homicides $(n=13,697)$, and $1 \%$ were unintentional firearm-associated deaths $(n=492)$. In fact, the annualized rate of firearm-related suicide was approximately $50 \%$ higher than the annual rate of firearm-attributed homicide (6.6 vs 4.4) and about 44 times the annual rate of unintentional mortality from firearms (WISQARS, 2017).

During this same span of time, more than 100,000 individuals received medical treatment in US emergency departments for a firearm-related injury due to an assault, act of self-harm, or unintentionally, for an overall mortality rate of $27 \%$ for all-types of firearm injuries. Furthermore, the estimated average annual age-adjusted firearm injury rate is 31.5 per 100,000 people. More than half of these cases resulted in hospitalization $(\mathrm{n}=54,060$ or $53.7 \%$ ) and about $39 \%$ were treated and released $(n=39,191)$. A small percentage of cases were observed in the ED or left against medical advice $(n=2,226 ; 2 \%)$. Unlike most causes of injury where deaths comprise a fraction of the total burden of injury, the average annual distribution of firearm-related deaths compared to hospitalizations was $27 \%$ versus $39 \%$. As it relates to $28 \%$ of violence-associated emergency department visits, this pattern of injury is quite similar across urban trauma centers and reflects the seriousness and lethality of firearm-related wounds (WISQARS, 2017).

According to the National Vital Statistics (NVS) Report for 2015, homicide estimates due to firearms occurred at higher rates among males and those aged 25-34 (Murphy et al, 2017). Furthermore, the highest rates for firearm-related aggravated assaults and homicides were notably among African-American males (WISQARS, 2017). It is not clear however, whether race or ethnicity is the primary causal factor driving these phenomena. In similar studies examining homicide rates in the city of Atlanta, and likewise in New Orleans, there appears to be variations in the rates of intra-racial domestic homicides (Centerwall B., 1995). This might be explained more so by social and economic factors rather than by race. Based on the postulation that poverty may lead to an increase in the likelihood of violence and aggressive behavior, analysis of race-related data is difficult to interpret and does not fully explain the racial differences.

Based on the NVS report, homicide by discharge of firearms was highest in non-Hispanic black males at a rate of 38.6 per 100,000 compared with 10.1 per 100,000 in Hispanic males and 19.4 per 100,000 in non-Hispanic white males (Murphy et al, 2017). Conversely, intentional self-harm by discharge of firearms was highest in non-Hispanic white males at 11.6 per 100,000 compared to 4.0 per 100,000 in Hispanic males and 5.3 per 100,000 in non-Hispanic black males (Murphy et al, 2017).
The potential years lost due to all preventable causes in the US in 2017 was 6,548 per 100,000 according to the Organization for Economic Cooperation and Development (OECD). However, the potential years of life lost (PYLL) due to suicide in the US is more difficult to ascertain. Data from Finland, suggests that PYLL in their country at ages $0-80$ is 3,960 years per 100000 inhabitants. These indicators describe the number of potential years of life lost due to suicide before the age of 80 per 100000 inhabitants.

\section{DISCUSSION}

Multiple risk factors contribute to the prevalence of assault-related gun violence in Georgia, including the spread of illicit drug use, gangs, the proliferation of firearms and alterations in the family structure, as well as changes in cultural norms, peer pressure and modern societal dynamics (Blumstein \& Wallman, 2000). Violent victimization or exposure is a significant public health issue that first affects individuals and then advances into the community. Sumner and colleagues described preventive strategies aimed at changing the individual mindset (Sumner et al., 2015). Some have suggested preventative measures involving youth should include the following recommendations: early childhood home visitation, parenting training, school-based social, psychological and emotional learning approaches, early childhood education, stronger public policies and therapeutic approaches to address post-traumatic stress disorder and depression. Through analysis of firearm-related violence data, the VPTF leadership influences and informs community partners on areas of concern and opportunities for improvement in the community. It also creates the platform for strategic alliance among group members to tackle problems of common concern.

Based on the above findings, our group sought to explore and further characterize the effects of gun violence on citizens in the state of Georgia. As gun violence is a condition that can negatively affect the health status of any victim, mounting data supports that firearm violence is a particularly lethal mechanism of injury. Although the literature suggests firearm-related aggravated assault due to interpersonal violence is more common among underrepresented minorities, especially in those ages 15 to 34 years old, there are additional key constructs as it relates to gun violence. Recognition of the demographic group at greatest risk for interpersonal related firearm violence helped us to focus and intensify our efforts in the area of youth mentoring of high school students, through programs such as Reach One Each One, our hospital-based youth mentoring and medical exposure program. We have also had the opportunity to testify before the Georgia state legislature to share our insight gained through analysis of the state specific WISQAR data. This approach is reproducible by other states and municipalities. 
The firearm-related case fatality rate (i.e., the proportion of gun-related injuries resulting in death), however, differs based on intent. In fact, suicide due to firearm injury has the highest gun-related case fatality rate by a greater than 4-fold. Furthermore, from 2015 to 2016, the national mean annual case fatality completion-rate was $84 \%$ for firearm-related suicide, versus $14 \%$ for gun violence-related assaults, and $2 \%$ for unintentional firearm injuries according to the 2017 CDC report. Sadly, the firearm-related injury patterns are no different in the state of Georgia and follow a very similar pattern. Therefore, who is at risk for firearm-related injury? The answer varies based on a variety of socioeconomic influences and demographic features. Some of the factors that distinguish population groups most at-risk for a firearm injury include age, gender, socioeconomic status, zip code and race/ethnicity among others. Based on this realization, our group invited a field expert in the area of suicide and suicide prevention to educate the members of our organization, including community partners through our Brown Bag luncheon lecture series. Furthermore, study of this data promoted partnership with and influence of our national medical organizations, American College of Emergency Physicians and the American Association for the Surgery of Trauma, to conduct workshops on "Lethal Means Interventions" and "Suicide and Suicide Prevention among Health Care Professionals," as a part of national convention pre-conference workshops.

The data we reviewed on firearm fatalities in Georgia is concerning. In 2016, according to the CDC's National Center for Health Statistics, Georgians were victims of 806 homicides and 1,571 total firearm deaths. The age-adjusted death rate attributed to homicide was 7.9./100,000 in GA compared to a national rate of $6.1 / 100,000$; whereas the age-adjusted death rate due to firearms was $15.0 / 100,000$ in Georgia compared to the national rate of $11.8 / 100,000$. This makes Georgia ranks as the 17th highest state based on firearm deaths and the 12th highest for homicide (NCHS, 2018). It is also worth noting that suicide and homicide were listed as the 2nd and 3rd leading cause of death, respectively, for both age groups of 15-24 and 25-34 in 2016 (WISQARS, 2017). The effect of these findings on the state's health system remains uncertain, although victims of penetrating violence related injury tend to be uninsured or underinsured compared to victims of blunt trauma, such as those due to motor vehicle collisions and falls. Presentation and discussion of this data at the 2019 Annual Spring Meeting of the Georgia Trauma Commission, Georgia Committee on Trauma (GA COT) and Georgia Committee on Trauma Excellence (GCOTE) led to the establishment of the Injury and Violence Prevention Committee under the GA COT by the Commission.

Furthermore, estimation of the annual cost to treat victims of gun violence is approximately \$202 million in Georgia (NVDRS, 2020). The additional societal costs for issues, such as insurance claims processing, work loss, quality of life costs, and criminal justice processing are estimated to be in the range of $\$ 3.1$ billion annually for the state (NVDRS, 2020). The approximate cost of non-gun related injuries is less clear. The long-term costs of chronic physical pain and post-traumatic stress (on both the individual and family) are difficult to quantify and even less well understood to the state and national health care system. To increase our understanding of this issue, one of the leaders of the task force was able to receive a grant to further study this matter in this at-risk population in the emergency room setting.

Unfortunately, the US has seen an increase in suicide rates since 2007. Different age groups show varying rates of suicide, with those between the ages of 50 to 54 at the largest risk for suicide (Fowler et al., 2015). Within that age group, there were 4,569 suicides in 2016, resulting in an age-adjusted death rate of 20.9. Out of all suicides committed in Georgia, 46\% $(n=2,127)$ of victims used a firearm. Interestingly, identification of self-harm using a firearm as the leading method of suicide attempts in the United States is enlightening and accounts for over half of all such deaths (Fowler et al., 2015). In fact, approximately two-thirds of the annual gun-related fatalities in America are suicide-related resulting in nearly 60 deaths per day (Fowler et al., 2015). In contrast to firearm-related interpersonal violence, which affects youth and underrepresented minority males at a higher rate, middle-aged and older Caucasian males tend to be at highest risk for attempted and completed firearm-related suicide. This realization could represent an unrecognized and under-appreciated mental health disparity.

Although most suicidal ideations and impulses are intense, they are usually short lasting, which makes early intervention imperative and potentially effective. As $84 \%$ of those who attempt firearm-related self-harm do not survive but die by suicide, this presents a significant problem and opportunity for the healthcare and public health system in the U.S. as well as the state of Georgia (Fowler et al., 2015; Simon et al., 2001). Establishment of a clear connection between firearms in the home and increased risk of suicide completion already exists. People who have access to these weapons are more likely to complete suicide than those who live in homes without guns (Dahlberg et al., 2004). Therefore, as suicide attempts with a gun are usually fatal, limiting access to guns in individuals with known mental illness makes sense and can decrease the opportunity for self-harm. Lethal means intervention or removal is a strategy that necessitates serious consideration and possible implementation by legislators, law enforcement and healthcare providers. Further study will be necessary to measure the impact as well as determine the best way to implement such a strategy on a statewide or societal basis. This information will also be useful to inform legislators and law enforcement through policy change and modifications of police practices, potentially.

Other methods used in suicide attempts tend to have a much lower case-fatality rates (e.g., cut/pierce injuries, $0.7 \%$; 
poisoning, 2.5\%; jumping/falling, 23.9\% (WISQARS, 2016). As Simon and colleagues have shown that suicides may be impulsive, the lethality of the method selected can be a critical determinant of whether the attempt is fatal or nonfatal. Prior research indicates that the time between deciding on suicide and attempting suicide is often impulsive and can be as little as 10 min or less (Simon et al., 2001, Deisenhammer et al., 2009). Furthermore, some evidence by Drum et al. suggests more people start an attempt and then stop mid-way than carry it through to completion (Drum et al., 2009). Unlike self-inflicted firearm injury or suicide by jumping from extreme heights, such as tall builds and high bridges, methods such as cutting, poisoning, and overdose provide an opening for an opportunity to rescue. It is also important to note that less than $10 \%$ of people that non-fatally attempt suicide go on to die by a self-inflicted injury (Owens et al., 2002). Previous research also indicates that most people use the same highly lethal method and do not deviate if that approach is unavailable or difficult to access (Hawton K. 2007). Consequently, the lethality of the mechanism available during an acute suicidal crisis can therefore make an important difference in the outcome. Removal of firearms from a suicidal person may be possible through implementation of temporary lethal means intervention laws.

In 2012, the three occupational categories with the highest identified rates of suicide were farming, fishing, and forestry; construction and extraction; and installation, maintenance, and repair (Table 1) (McIntosh et al, 2016). Together these high-risk occupations account for $7.9 \%$ of total employment within Georgia, and disproportionately affect rural communities (Bureau of Labor Statistics, Occupational Outlook Handbook 2017).

Table 1

Rates of suicide by gender per 100,000 population based on Standard Occupation Classification (SOC) group

\begin{tabular}{l|c|c|c|}
\hline \multicolumn{1}{|c|}{ Occupational group } & Overall & Male & Female \\
\hline Farming, fishing, and forestry & 84.5 & 90.5 & - \\
\hline Construction and extraction & 53.3 & 52.5 & - \\
\hline $\begin{array}{l}\text { Installation, maintenance, } \\
\text { and repair }\end{array}$ & 47.9 & 47.5 & 10.8 \\
\hline Production & 34.5 & 39.5 & - \\
\hline $\begin{array}{l}\text { Architecture and engineering } \\
\text { Protective service }\end{array}$ & 32.2 & 36.3 & 14.1 \\
\hline $\begin{array}{l}\text { Arts, design, entertainment, } \\
\text { sports, and media }\end{array}$ & 30.5 & 34.1 & 12.4 \\
\hline $\begin{array}{l}\text { Computer and mathematical } \\
\text { Transportation and material } \\
\text { moving }\end{array}$ & 24.3 & 32.9 & 12.5 \\
\hline $\begin{array}{l}\text { Total } \\
\text { * Rates were calculated using data from the U.S. Census Current Population Survey March supplement. }{ }^{+} \text {Rates were } \\
\text { not calculated where the decedents were fewer than 20 because those estimates might be unreliable. }\end{array}$ \\
$\begin{array}{l}\text { Mclntosh WL, Spies E, Stone DM, Lokey CN, Trudeau AT, Bartholow B. Suicide Rates by Occupational Group - } 17 \text { States, 2012. } \\
\text { MMWR Morb Mortal Wkly Rep 2016;65:641-645. DOI: http://dx.doi.org/10.15585/mmwr.mm6525a1 }\end{array}$
\end{tabular}

Note. Data as ranked overall by 17 states in 2012*. Suicide rates were highest for workers in the farming, fishing and forestry industry followed by construction and extraction.

Data supports that first-line supervisors of retail sales workers, cashiers, police and sheriff's patrol officers, and taxi drivers saw the largest number of workplace homicides in 2015 (Bureau of Labor Statistics, Workplace Homicides 2017). In Georgia, $4.1 \%$ of employed residents are in one of these four professions. When taken in context, this data indicates that $12 \%$ of Georgians are at an increased risk of violent self-injury, which calls for a need to address this statewide issue. The VPTF believes these findings can help shed light on such issues and lead leadership to direct greater resources to this area. Because of the job loss situation and isolation due to COVID-19 pandemic and an increase in firearm sales, there is concern that firearm-associated suicides and homicides might be increasing. Analysis and ongoing monitoring of similar data by from the NVDRS and WISQARS databases by similar 
Task Forces and/or private, community-based or governmental entities may provide the insight needed to coordinate an appropriate public health response to the potential sequelae.

One profession in need of specific mention is law enforcement, as members are actively involved in situations heavily impacted and intertwined with violent injuries. In 2015, the CDC report attributed 358 violent deaths to the actions of police officers throughout the United States (WISQARS, 2016). In addition to the implications for these lost lives, workplace-related trauma greatly influences the psychological standing of the officers and contributes to their $82 \%$ increased rate of suicide found amongst detectives and police Violanti et al., 2013). A New Zealand study found that $74 \%$ of new police recruits experienced at least one traumatic event within their first year. Furthermore, the investigation showed that officers who experienced such a traumatic event were more likely to report symptoms of PTSD and therefore were more likely to experience suicidal ideation (Huddleson et al., 2007). In order to help combat this multifaceted issue, community-based intervention programs such as the implementation of a Crisis Intervention Team (CIT) is one strategy that the VPTF suggests. However, it must occur on a larger scale. The CIT trains officers to handle situations involving people with mental illnesses, de-escalate violence and conflict peacefully, and coordinate immediate psychiatric care, as necessary. Although there has been a distinct lack of randomized, controlled trials of CIT, initial studies of CITs have shown decreased arrest rates of those with mental illnesses, increased mental health service utilization, and decreased force with resistant subjects (Watson \& Fulambarker, 2012). Given the success of CITs and the estimate that $10 \%$ of police-public encounters involve someone with mental illness, it is imperative that full utilization of CITs, and similar programs, ensues in Georgia and throughout the country. This is an area where political, judicial and civic leaders can have an immediate influence. Partnerships through the VPTF and IPRCE can serve as a vehicle to bring much needed attention to this matter.

The potential years lost due to all preventable causes in the US in 2017 was 6,548 per 100,000 according to the Organization for Economic Cooperation and Development (OECD). However, the potential years of life lost (PYLL) due to suicide in the US is more difficult to ascertain (PYLL, OECD, 2018). Data from Finland, suggests that PYLL in their country at ages $0-80$ is 3,960 years per 100 000 inhabitants. These indicators describe the number of potential years of life lost due to suicide before the age of 80 per 100000 inhabitants. The basis for the age 80 referenced is the average life expectancy of the Finnish population. The basis for their estimation of PYLL due to suicide is the documented cause of death in their Cause of Death Statistics registry (PYLL, OECD, 2019).
Nationally, the suicide rate increased 25.4\% from 1999 to 2016, with increases occurring in every state, except Nevada. In 2017, there were an estimated 1.4 million suicide attempts and over 47,000 related deaths, making it the 10th leading cause of death in the U.S. (America's Health Ranking, 2019). Firearms were involved in over half of all suicide deaths, highlighting the deadly nature of guns when used for self-harm. The suicide rate in Georgia is 14.1 per 100,000 compared to 14.5 nationally. On the other hand, the suicide rate for White males was 18.4 for Georgians versus 16.4 across the U.S. (America's Health Ranking, 2019). However, stratification based on PYLL is not the commonly reported approach in Georgia or the US. This alternate approach to reporting suicide to policy makers and funders might help to increase the level of funding and research in this important but highly unrecognized opportunity to improve the safety of Georgians.

Close association of suicides with mental disorders, especially depression, is a strong theoretical concern. However, other plausible risk factors for suicide are previous suicide attempts, alcohol and drug abuse, suicides in close relationships, poor socio-economic status, unemployment, and loneliness (America's Health Ranking, 2019). Suicides are more common among men. Tracking PYLL due to suicide may be beneficial in the state of Georgia and throughout the US and as it might help direct appropriate resources to this under-appreciated area of need. Furthermore, it could help to shed greater light on the true severity of the gun violence epidemic, which continues to plague America. In Finland, both regional and national suicide prevention programs have shown some success in reducing the number of suicides. The key principles for their suicide prevention effort are early identification of people at risk and mitigation of risk factors (PYLL, OECD, 2019). Based on the Finnish study, the more commonly accepted indicators of increased suicide risk include individuals with recent prior suicide attempts, depression, alcohol use disorder, lack of social support, poor crisis management or coping skills, social exclusion, stigmatizing, and bullying (PYLL, OECD, 2019).

Remedies for these risk factors include providing necessary support, appropriate treatment of depression and other mental conditions, alternative coping skills training, conflict resolution training, professional counseling and support, and increased education, opportunity and faith in life. Strategies to build courage, self-esteem, initiative, and mutual support may provide hope and enhance resilience against suicidal ideations and attempts (America's Health Ranking, 2019). Increased research funding to study psychosocial interventions specially to address the issues of gun violence, including suicide and aggravated assault would strengthen our understanding of the best way to reduce harm due to this quietly devastating problem of fatal self-harm due to firearm-related violence. As the availability of firearms plays a central role in the victim's ability to complete a 
suicidal act, another strategy that gaining traction and showing hints of success is lethal means intervention. Removal of the deadly weapon during the time of crisis and suicidal ideation period allows time for resolution of the acute stimulating event or situation. Furthermore, stratification of this data enhances the understanding and knowledge of the real impact of suicide for healthcare professionals in the mental and behavioral health field.

In an article by Stevens entitled "How can you blame a 2-year-old' for finding and firing an adult's gun?" wide-ranging availability of guns in households in the state and lack of gun safety practices in general was illuminated in the Atlanta Journal Constitution (AJC) Investigation. The article appeared on the front page of the AJC on February 26, 2017 and the focus was on children and accidental shootings deaths in Georgia. The report revealed that in 2015 seventeen children were the victims of unintentional shootings by other children or themselves in Georgia. In addition, the shooting of two children by their mothers, one of whom died, was devastating. In total, nine died from accidental shootings (Stevens A, 2017). The 2016 numbers were higher with 12 young Georgians killed in 23 shootings. While there is no official count of how many children are involved in unintentional shootings, gun safety advocates place Georgia in the top three states for the most incidents, along with Florida and Texas.

When a child finds loaded weapons and shoots himself/herself or someone else, the owner of the gun is not always the one held responsible. An investigation by The Atlanta Journal-Constitution and Channel 2 Action News in Atlanta examined 42 shootings in Georgia in 2015 and 2016 and found a wide range of actions taken by police (Stevens A, 2017). The report revealed that law enforcement did not charge all gun owners equally, even when a child died from the gunshot wound. In fact, an analysis of the shootings showed if the owner of the gun was black, police were much more likely to charge them with a firearm-related crime, while white gun owners avoided any charges (Stevens A, 2017). Consequently, the findings of this investigation can influence policy on how law enforcement charge and process gun owners whose gun is the weapon used in such events as unintentional shootings.

Not surprisingly, teenagers were the victims in slightly more than one-third of the 42 unintentional shootings of children the AJC and news station examined. The youngest victims were 1-year-olds, and 17 were 5 years old or younger. All but eight of the Georgia victims were boys. The racial breakdown was as follows: 25 were African-American, 11 were white, two were Hispanic, and one was Asian. Of the completed investigations, filing of charges occurred in roughly half the cases (Stevens A, 2017). When the victims and gun owners were black, 70 percent were charged. Of the 42 shootings involving children, three were unidentified by name, so their race could not be ascertained. Georgia laws are not specific regarding the handling of unintentional shootings, and that makes it difficult for investigators, according to police agencies. In the Georgia cases, about half of the shootings were self-inflicted. Other times, the child shot another child or an adult, often a family member or close friend.

Although the details may differ from case to case, the startling sound of unexpected gunfire changes lives in a split second. To put the matter into better perspective, three children died in separate incidents during a one-month period in the fall of 2015, according to the report (Stevens A, 2017). When children are exposed and/or injured due to firearm related injury at a young age, it is by definition an adverse childhood event (ACE). ACEs negatively affect the personal growth, emotional development and long-term well-being of afflicted young people. Furthermore, when a young person sustains a permanent disability due to an unnecessary gun-related injury, or worse dies from senseless firearm violence, the catastrophic event effectively eliminates them from the current and future workforce. Consequently, they are not able to reach their full potential professional potential, which ultimately has a negative long-range impact on our society through depletion of trainable human resources to support the growth of the economy. Instead of becoming productive members of society, permanent injury due to gun violence in Georgia increases the cost of healthcare and places additional burden on the state's economic system for the ongoing care of the victim.

On the other hand, domestic violence (DV) is another sector of the firearm discussion that requires careful examination and greater attention. In 2015 report, the CDC found that 5.7 million men and 6.5 million women had experienced contact sexual violence, physical violence, and/or stalking by an intimate partner within one year of being surveyed (WISQARS, 2016; Smith et al., 2016). Despite the high incidence of domestic violence, only a small percentage of victims died due to injury. Importantly, out of the fatalities resulting from DV, firearm-related violence contributes to a high proportion of these types of casualties. During the same year in the US, out of the 788 reported cases of domestic violence resulting in death, in $60.5 \%$, or 477 , a firearm was used (WISQARS, 2015). The situation is even more striking in Georgia, which ranked 8th in the nation for highest number of female victims of contact sexual violence, physical violence, and/or stalking by an intimate partner (Smith et al., 2018).

In 2015, there were also 82 deaths attributed to domestic violence and 66 of these deaths in the state were due to a firearm, accounting for $80.5 \%$ of the total DV-related fatalities (WISQARS, 2016). In order to combat intimate partner violence-related homicide (IPH), states such as California have instituted laws that require those with intimate partner violence (IPV) related restraining orders, or IPV misdemeanor/felonies to relinquish their firearms. A study investigating the impact of such laws has shown that 
they were associated with a $9.7 \%$ decrease in total IPH and a 14\% decrease in IPH via firearm (Diez et al., 2017). Implementing similar laws and programs in Georgia could prove effective in reducing the state's high IPH rate. Information learned from this study might go a long way in influencing policy makers to enact laws that protect victims of IPH in GA.

Just as important as the issue of violence is the type of weaponry utilized to commit self-harm related injury and aggravated assaults. When assailants utilize assault rifles, these violent events tend to be particularly deadly and devastating. The common theme surrounding the utilization of assault weapons is their ability to fire a large number of bullets rapidly, thereby allowing for multiple sites of serious injury to numerous people in a short period. With the increased use of these types of weapons in the perpetuation of mass-shootings, there has come a huge outcry by the public for more stringent regulation of the availability of this means of weaponry. Existing data supports such an approach.

An Australian study demonstrated that a prohibition of rapid-fire assault-style weapons reduced the occurrence of mass shootings over the decade studied (Chapman et al., 2006). However, data are not available for the U.S. because, although the banning of assault weapons transpired in 1994, the repeal of this restriction followed in 2004. Consequently, in the past legislation limited the ability of researchers to collect scientific and/or medical data regarding the probable effect of this style of weaponry, which prohibited the CDC and similar governmental agencies from engaging in federally funded gun-related research dating back to 1996 (Blumstein \& Wallman, 2005). Nevertheless, this remains a research question worth pursuing. However, for conduction of this type of research on a statewide level, we will have to harness the resources of our Public Health partners and develop the ability to connect and explore local, regional, state and national law enforcement and FBI databases as well. Efforts to understand the full effect of assault-style weapon use need updating and standardization. Likewise, data sharing between states, law enforcement, healthcare organizations, and other agencies must be undertaken and needs to be unhindered in order to help improve awareness and reduce unintentional firearm injuries, particularly as it relates to assault-style weapons.

Performing the above research afforded the VPTF the opportunity to participate on a state legislative panel discussion and hearing regarding use of assault style weapons in Georgia. Similarly, redefining understanding of firearm-related injury in other states and urban communities can serve as a vehicle for partnership with lawmakers and community organizations and leaders to effect positive change as it relates to interpersonal and self-inflicted gun violence.

\section{SUMMARY OF POLICY RECOMMENDATIONS}

\section{Policy Recommendation 1: Regarding Reducing the Impact of Gun-Related Violence}

Based on the finding of our research, review of NVDRS and WISQARS enhances understanding of how firearm-related violence directly affects health care costs, increases inequality, and decreases human capital, and thereby potentially diminishing economic growth in states, which is a high priority objective in Georgia. The VPTF, in alignment with the Center for Disease Control and Prevention's (CDC's) Epidemic Intelligence Service approach to combating violence, strongly recommends expansion of similar violence prevention research and strategies to affected communities throughout Georgia that can impact the multiple forms of violence directly, which are ravaging our neighborhoods.

The VPTF suggests implementation of preventative measures involving youth should include the following recommendations: early childhood home visitation, parenting training, school-based social, psychological and emotional learning approaches, early childhood education, stronger public policies, youth mentoring and therapeutic approaches to address post-traumatic stress disorder and depression. Implementation of hospital-based or community-based youth mentoring and professional role modeling programs, such as ROEO, may serve as a model to help mitigate community violence once identified and quantified via analysis of such databases.

\section{Policy Recommendation 2: Reducing the Incidence and Impact of Firearm-Associated Suicide}

Although literature supports limited access to firearms leads to fewer deaths, more alarming is the high rate of suicide deaths resulting from firearms. It is the position of the VPTF that increased funding is necessary in this area to conduct research and institute programs to address this serious but under-recognized source of harm to Georgians. Extrapolating from data from European countries and studies where gun availability is restricted, we recommend implementation of strategies that elucidate the etiology of self-inflicted gun violence, which may prove even more effective. Whereas about eighty-five percent of suicide attempts with a gun are fatal, only $2 \%$ of attempts via medication or illicit drug overdose result in death. These data underscore the critical role access to firearms tends to have on the more lethal outcomes, whether the use is against oneself or someone else is the victim.

Therefore, as suicide attempts with a gun are usually fatal, we recommend evaluating legislation which would limit access to guns and decrease the opportunity for self-harm for individuals with active psychotic mental health disease and/or known suicidal ideations as a form of Lethal Mean Intervention. Furthermore, the findings of this and similar 
studies can inform legislators, healthcare professionals and law enforcement through outreach, education and community engagement. Additional funding to investigate age-group specific interventions based on known associated risk factors would be beneficial.

\section{Policy Recommendation 3: Reducing the Impact of Assault-style Firearm-related Violence}

Although the information regarding the impact of "assault weapons" remains controversial, there is continued debate as to what constitutes an assault weapon. In fact, most mass shootings since the Columbine incident almost 2 decades ago have involved some type of semi-automatic assault-style weapon. More recently, the Sandy Hook shooting, which took the lives of nearly 2 dozen children, involved the use of an AR-15 Bushmaster assault rifle. In the Las Vegas shooting incident, the assailant used bump stock on the assault rifles to increase the number of rounds of bullets fired per gun. The common theme surrounding the utilization of these types of weapons is their ability to fire multiple bullets rapidly thereby allowing for multiple sites of serious injury to numerous people in a short time period. Another question is, "Do these military-style weapons belong on U.S. streets or in American homes?"

We recommend increased funding of research that will enhance our understanding of the use and safety of assault weaponry in our society. We support legislation to restrict bump stock that increases the capacity of gun magazines in the state. Furthermore, our findings support Georgia legislation that would place a ban on assault-style weapons and/or limit the capacity of magazines associated with these types of guns, which would reduce the potential for mass shooting over the decades to come. A dialogue that allows focus on the health impact of firearms is necessary to proceed with as little political influence as possible. For that reason, the VPTF joins with the American College of Surgeons, the American Academy of Pediatrics, the American Association for the Surgery of Trauma, the Society of Black Academic Surgeons and other healthcare organizations in recommending similar measures to reduce the impact of firearm violence. The VPTF agrees with the Epidemic Intelligence Service's approach put forth by the CDC to combat violence. We strongly recommend expansion of violence preventative strategies and legislation that will address multiple forms of violent injury, particularly firearm-related violence and suicide and reduce the associated morbidity and mortality. Through partnership with our legislative leaders as medical subject matter experts, using the results of such analyses is valuable for bringing about changes in laws to protect our communities and the individuals that we serve.

\section{Policy Recommendation 4: Evaluate Policing Policy}

In light of the recent and other historic events related to police violence, we recommend systematic investigation and internal and external evaluation of policing policies, practices and procedures. Furthermore, we support the development of a community-led policing monitoring program for every police department. We believe that police partnership with a responsible citizen's council will lead to a sustainment of law, order and peace throughout our cities, neighborhoods and state. Furthermore, based on our findings related to suicide among police, we recommend increased access and availability to mental health services and non-lethal violence de-escalation training for all members of law enforcement.

The Violence Prevention Task Force concurs with the other national and regional medical organizations, including the American College of Surgeons, American College of Emergency Physicians and American Foundation for Firearm Injury Reduction in Medicine (Taichman et al., 2018) and makes the following recommendations:

1. Development of an evidence-based informed state research agenda that would help governmental, law enforcement and healthcare leaders to understand the full scope of gun-related violence.

2. Eliminate restrictions on the types of research questions that investigators can use federally funded resources to explore. Seek state and federal resources through the Indigent Care Fund, private philanthropic foundations, the Centers for Disease Control (CDC) and the National Institutes of Health (NIH) to coordinate this agenda.

3. Solicit federal, state and local funding to increase programs such as the Nurse-Family partnership, Families First, The Atlanta Women's Foundation, Year Up, and other parent management and life skills development training programs.

4. Support legislation that allows physicians to recommend that firearm access removal from individuals with schizophrenia, depression, suicidal ideations, drug abuse, impulsivity, or a mental or neurologic illness, especially one that places the individual or others at significant risk of harm due to the presence or use of a firearm.

5. Encourage enhanced availability of state and local funding to increase programs such as trauma center-associated, hospital-based, and community-based violence prevention and intervention partnership programs.

6. Increase funding to study and treat mental illness, suicidal ideation and firearm restriction in people at increased known risk for attempted suicide or self-harm or aggravated assault.

7. Support legislation that allows physicians and law enforcement to promote and advocate firearm safety, firearm safety training and removal of firearm access from children, individuals with known suicidal ideations, and/or other significant and diagnosed mental illness.

\section{CONCLUSION}

There are many forms of violence that affect the citizens of the state of Georgia and this nation, which have not been reviewed, discussed or addressed in this document, 
including family/domestic violence, sexual violence, bullying, etc. However, it is not an overreach to postulate that many of the issues described regarding gun-related interpersonal violence and the impact of exposure to firearms and firearm-related injury likely apply to some degree in these other areas. There are limited data on firearm-related violence prevention and interventions that may already exist and show promise. What is known for certain is we need evidenced-based data and increased public awareness and education on the impact of firearm-associated interpersonal violence and gun-related self-harm or suicide on our citizens, and particularly our youth, ethnic minorities, our elderly, and other underrepresented communities in the state of Georgia.

Although the years of lost life and productivity are under-appreciated, analyzing firearm-related violence from this perspective can aid decision makers and community advocates in shaping their perspective related to this significant public health crisis. The VPTF remains committed to research, education and advocacy to prevent community-oriented interpersonal violence, suicide, and all forms of firearm-related injury. Furthermore, the VPTF proposes to continue to support our community partners as well as the expansion of the knowledge base of our state and nation in the areas such as firearm violence, self-harm/suicide and injury prevention. As such, we strongly encourage and support continued public and private partnerships with entities, such as the Georgia Department of Public Health, state legislators, and national professional organizations and making efforts on a national, state, and local-regional level to address gun violence and violence prevention in all its forms. Similarly, redefining understanding of firearm-related injury in other states and urban communities can serve as a vehicle for partnership with lawmakers and community organizations and leaders to effect positive change as it relates to interpersonal and self-inflicted gun violence.

\section{References}

America's Health Ranking. Annual Report. (2019) United Health Foundation, Retrieved from

https://www.americashealthrankings.org/explore/annual/measur e/YPLL/state/CA

Blumstein, A \& Wallman, J. (Eds.). The Crime Drop in America (Cambridge Studies in Criminology). Cambridge: Cambridge University Press. (2000).

Blumstein, A \& Wallman, J. The Crime Drop in America (Cambridge Studies in Criminology). (2005). Cambridge: Cambridge University Press, 2nd Edition.

Bureau of Labor Statistics, U.S. Department of Labor. (2017). Occupational Outlook Handbook, State Occupational Employment and Wage Estimates Georgia. Retrieved from https://www.bls.gov/oes/current/oes_ga.htm\#45-0000 (visited July 3, 2018).

Bureau of Labor Statistics, U.S. Department of Labor.(2018) Occupational Outlook Handbook, Workplace Homicides. Retrieved from https://www.bls.gov/iif/oshwc/cfoi/workplace-homicides.htm (visited July 3, 2018).
Centers for Disease Control and Prevention, National Center for Injury Prevention and Control. (2015). Web-based Injury Statistics Query and Reporting System (WISQARS). [2015 November 16]. Retrieved from https://www.cdc.gov/injury/wisqars/fatal.html

Centers for Disease Control and Prevention, National Center for Injury Prevention and Control. (2016). Web-based Injury Statistics Query and Reporting System (WISQARS). [2016 December 15]. Retrieved from https:/www.cdc.gov/injury/wisqars/facts.html

Centers for Disease Control and Prevention, National Center for Injury Prevention and Control. (2017). Web-based Injury Statistics Query and Reporting System (WISQARS). [2017 November 15]. Retrieved from https://www.cdc.gov/injury/wisqars/facts.html

Centerwall, B. Race. (1995) Socioeconomic Status, and Domestic Homicide, JAMA. 273(22): 1755-8.

Chapman, S, Alpers, P, Agho, K, Jones, M. (2006). Australia's 1996 Gun Law Reforms: Faster Falls in Firearm Deaths, Firearm Suicides, and a Decade without Mass Shootings. Inj Prev 12(6):365-72.

Dahlberg, L, Ikeda, R, Kresnow, M. (2004). Guns in the Home and Risk of a Violent Death in the Home: Findings from a National Study, Amer J of Epidemiology, 160(10,15):929-936. Retrieved from

https://doi.org/10.1093/aje/kwh309

Deisenhammer, E, Ing, C, Strauss, R, Kemmler, G, Hinterhuber, H, Weiss, E. (2009). The duration of the suicidal process: how much time is left for intervention between consideration and accomplishment of a suicide attempt? J. Clin. Psychiatry. 70(1):19-24.

Díez, C, Kurland, R, Rothman, E, Bair-Merritt, M, Fleegler, E, Xuan, Z, et al. (2017). State Intimate Partner Violence-Related Firearm Laws and Intimate Partner Homicide Rates in the United States, 1991 to 2015. Ann Intern Med. 167:536-543. Retrieved from doi: 10.7326/M16-2849.

Drum, D, Brownson, C, Denmark, A, Smith, S. (2009). New data on the nature of suicidal crises in college students: shifting the paradigm. Prof. Psychol. Res. Pract. 40(3):213-222.

Fowler, K, Dahlberg, L, Haileyesus, T, \& Annest, J. (2015). Firearm Injuries in the United States. Preventive Medicine, 79, 5-14.

Hawton, K. (2007). Restricting access to methods of suicide: rationale and evaluation of this approach to suicide prevention. Crisis, 28(1):4-9.

Huddleson L, Stephens C, Paton D. (2007). An Evaluation of Traumatic and Organizational Experiences on the Psychological health of New Zealand Police Recruits. Work, 28:199-207.

McIntosh, W, Spies, E, Stone, D, Lokey, C, Trudeau, A, \& Bartholow, B. (2016). Suicide Rates by Occupational Group 17 States, 2012. Centers for Disease Control and Prevention MMWR, 65(25), 641-660.

Murphy, S, Xu, J, Kochanek, K, Curtin, S, Arias, E.( 2017 ). Deaths: Final data for 2015. National Vital Statistics Reports; Hyattsville, MD: National Center for Health Statistics, 66(6).

National Center for Health Statistics. (2018). Retrieved from https:/www.cdc.gov/nchs/pressroom/states/georgia/georgia.htm

National Violent Death Reporting System. (Accessed 2020, February 18).

Retrieved from

https://www.cdc.gov/violenceprevention/datasources/nvdrs/inde x.html; and https://wisqars.cdc.gov:8443/nvdrs/nvdrsDisplay.jsp

Owens, D, Horrocks, J, House, A. (2002). Fatal and non-fatal repetition of self-harm. Systematic review. Br. J. Psychiatry. 181:193-199. 
Potential Years of Life Lost. (2018). Organization of Economic Cooperation and Development. Retrieved from

https://data.oecd.org/healthstat/potential-years-of-life-lost.htm

Potential Years of Life Lost Due to Suicide at ages 0-80 per 100,000 inhabitants. (2019). Finnish Institute of Health and

Welfare. Retrieved from https://sotkanet.fi/sotkanet/en/metadata/indicators/3960

Simon T, Swann A, Powell K, Potter L, Kresnow M, O'Carroll P. (2001) Characteristics of impulsive suicide attempts and attempters. SLTB.

32(supp):49-59.

Smith, S, Chen, J, Basile, K, Gilbert, L, Merrick, M, Patel, N, Walling, M, \& Jain, A. (2017). The National Intimate Partner and Sexual Violence Survey (NISVS): 2010-2012 State Report. Atlanta, GA: National Center for Injury Prevention and Control, Centers for Disease Control and Prevention.

Smith, S, Zhang, X, Basile, K, Merrick, M, Wang, J, Kresnow, M, Chen, J. (2018). The National Intimate Partner and Sexual Violence Survey (NISVS): 2015 Data Brief. Atlanta, GA: National Center for Injury Prevention and Control, Centers for Disease Control and Prevention. Retrieved from https://www.cdc.gov/violenceprevention/pdf/2015data-brief508. pdf
Stevens, A. (2017). Kids \& Guns: The toll of accidental shootings involving children. Atlanta Journal Constitution. A11. Retrieved from

http://photos.imageevent.com/rockbobcat/coxohio/ajc/2017/AJC A11022617BD.pdf

Sumner, S, Mercy, J, Dahlberg, L, Hillis, S, Klevens, J, Houry, D. (2015). Violence in the United States: Status, Challenges, and Opportunities. JAMA. 314(5):478-488.

Retrieved from doi:10.1001/jama.2015.8371.

Taichman, D, Borstein, S \& Lane, C. (2018). Firearm Injury Prevention: AFFIRMing Doctors are in Our Lane. American Foundation for Firearm Reduction in Medicine (AFFIRM). Retrieved from https://affirmresearch.org/. https://doi.org/10.7326/M18-3207

Violanti, J, Robinson, C, \& Shen, R. ((2013). Law enforcement suicide: A national analysis. IntJ Emerg Ment Health \& Hum Resil, 15(4):289-298.

Watson, A \& Fulambarker, A. (2012). The Crisis Intervention Team Model of Police Response to Mental Health Crises: A Primer for Mental Health Practitioners. Best Pract in Ment Health, (2):71.

(C) Omar K. Danner, Lauren Hudak, Rana Bayakly, Carol Koplan, Alexander Kelly, Sharon L. Nieb, and Sheryl L. Heron. Originally published in jGPHA (http:/www.gapha.org/jgpha/) July 24, 2020. This is an open-access article distributed under the terms of the Creative Commons Attribution Non-Commercial No-Derivatives License (http://creativecommons.org/licenses/by/4.0/), which permits unrestricted use, distribution, and reproduction in any medium, provided the original work ("first published in the Journal of the Georgia Public Health Association...") is properly cited with original URL and bibliographic citation information. The complete bibliographic information, a link to the original publication on http://www.gapha.jgpha.org/, as well as this copyright and license information must be included. 